\title{
SIMULATION OF GEOELECTRICAL RESPONSES OF STRUCTURES BURIED IN FRESHWATER AND BRACKISH WATER ENVIRONMENTS
}

OPEYEMI JOSHUA AKINRINADE, TOLULOPE EMMANUEL OGINNI AND ELNALEE BUYAGAO BAGUYA

(Received 18 March 2020; Revision Accepted 17 November 2020)

\begin{abstract}
Marine geoelectrical simulation offers the opportunity to predict matrix type, interstitial fluid and geometry of buried structures. In this research, simulation of geoelectrical responses over buried structures in freshwater and brackish water environments were tested. A model tank made of acrylic and housed within an iron frame was built for the experiment. The tank was filled with water and sieved sediment having grain sizes $\leq 1.18 \mathrm{~mm}$, corresponding to very coarse sand to colloid. Four models were designed namely freshwater static model (FSM), brackish water static model (BSM), freshwater model with buried structures (FMBS), and brackish water model with buried structures (BMBS). A bamboo pipe, metal pipe and granite block were buried in the FMBS and BMBS. Physico-chemical parameters of the water which includes temperature $\left(22.74-26.06{ }^{\circ} \mathrm{C}\right)$, salinity $(0.07-15.72 \mathrm{psu})$, conductivity $(153-25,420 \mu \mathrm{S} / \mathrm{cm})$ and resistivity $\left(5.6 \times 10^{3}-6.6 \times 10^{3} \Omega\right.$-cm) were measured. Dipole-dipole array using inter-electrode separation (a) of $5 \mathrm{~cm}$ and $1 \leq n \leq 5$ was adopted. Resistivity measurements obtained were processed and inverted using non-linear least-square optimization technique. We present obtained results as contoured 2D resistivity structures. FSM and FMBS were characterized by relatively high resistivity values compared with the BSM and BMBS. The buried materials were effectively resolved in the freshwater models, compared to the brackish water model due to higher contrast in resistivity between the material and saturating fluid. The bamboo pipe was not effectively delineated in the brackish water medium, as a result of the low resistivity contrast which exists between the medium and the material. Zones with high compaction are characterized by high resistivity values, while concealed channel structures were characterized by low compaction. Estimated depth were exact for the freshwater models but was over estimated by $\sim 12.5 \%$ in the brackish water models. Marine electrical resistivity method shows great potential in mapping structures buried in medium with high contrasting resistivity values, and sedimentary structures with varying degree of compaction.
\end{abstract}

KEYWORDS: Marine electrical resistivity, geoelectrical simulation, buried structures, modeling, electrical resistivity

\section{INTRODUCTION}

Marine electrical resistivity method like the terrestrial equivalent utilizes the contrast in material properties to identify possible target locations (Baumgartner et al., 1996; Baumgartner and Christensen, 1998; Yang et al., 2002; Passaro, 2010). It has a broad spectrum of applications which include engineering and environmental investigations, as well as detecting buried subsurface anomalies of archeological significance at different depths (Leucci et al., 2007; Compare et al., 2009). In addition, it has been used to delineate the spatial and temporal distribution of freshwater and brackish water interface in coastal setting (Henderson et al., 2010; Obikoya and Bennell, 2012). This method is known for almost four decades, but its applications are actually rare as confirmed by the lack of references in literature (Passaro, 2010).
Marine geoelectrical simulation offers the opportunity to predict responses, structures, matrix type, and interstitial fluid in earth materials. It presents the earth system and associated processes which can be studied using nonintrusive approach. This method is suitable for studying earth processes within the marine domain where accessibility is greatly limited. Laboratory simulation is a concept from which we can deduce effects and comparison with observations, which is essential in terrains characterized by complex geology and limited geophysical records (Morakinyo, 2015). Also, it has become a vital tool in interpretation of geophysical data when the signature produced in the field by a particular effect is non-unique and subject to further analysis.

Geoelectrical simulation involves the generation of electrical responses over two or three dimensional (2D or 3D) structures with known geometry; positioned within earth materials with contrasting physical properties. The

OPEYEMI JOSHUA AKINRINADE, Ocean College, Zhejiang University Zhoushan, China; Marine Science and Technology, the Federal University of Technology, Akure, Nigeria

TOLULOPE EMMANUEL OGINNI, Ocean College, Zhejiang University Zhoushan, China; Marine Science and Technology, the Federal University of Technology, Akure, Nigeria

ELNALEE BUYAGAO BAGUYA, Ocean College, Zhejiang University Zhoushan, China; 
use of models in prospecting is a useful aid in the interpretation of geoelectrical responses over bodies of different shapes, sizes and dimensions. Potential methods (i.e. gravity and magnetics) and electromagnetic methods are areas that have attracted much research using geometric models such as spheres, cylinders, sheets and slabs of different orientations and have been used to simulate dykes, faults, anticlines, etc (Lelievre and Oldenburg 2006, Butler and Sinha 2012). A successful simulation experiment helps to better understand field signatures over target bodies.

Terrestrial applications, simulating geoelectrical responses have been applied to engineering and environmental problems by various authors (Olorunfemi et al., 2001; Adepelumi et al., 2006; Kaufmann and Deceuster, 2007). Example includes 2D simulation of geoelectrical response over hydrocarbon impacted sand formation which offers the opportunity to determine the fate and effect of hydrocarbon in porous and permeable sediment (Moradi 2011, Subba and Chandrashekhar 2014). Result obtained for varying electrode configuration offers the opportunity to determine sensitivity of an array to the test model. Dipole-dipole electrode configuration indicates that while the limits of spill can be accurately defined, its depth extent may be slightly overestimated. It shows an increase in resistivity of about $40 \%$ in highly polluted areas (Kaufmann and Deceuster, 2007). Simulating geoelectrical responses and electrode sensitivity over a two-layer earth model reveal that pole-pole array is most suitable for imaging tunnel structures, Wenner-Schlumberger and Wenner for imaging dyke (Morakinyo, 2015).

In this research, we investigate the application of marine electrical resistivity in freshwater and brackish water domain, with the aim to determine geoelectrical responses over concealed structures. This is carried out through laboratory simulation and inversion of measurement obtained. It is noteworthy that published articles on marine geoelectrical simulation or resistivity measurements are rare. Possibly due to accessibility and competing alternative techniques such as seismic method which is generally applied in the marine domain. Though, multi-channel reflection seismic provide fast and accurate result, but standard seismic data acquisition system and data processing are quite challenging to execute in very shallow water or transition zone as the size of the source vessel and air-gun array is restricted, which impact on the data quality (Miller et al., 1995; Kitson, 1996; Mosher and Simpkin, 1999; Shtivelman, 2001).Therefore, development of marine electrical resistivity method promises to provide a relatively low cost, non-invasive, and rapid means to generate subsurface earth models. It provides an alternative or a complementary method to seismic prospecting in very shallow water environment (Passaro, 2010). The result of this experiment will aid the interpretation of marine electrical resistivity anomalies over similar geologic or engineering structures.

Material and method

The following materials were used for the study: a model tank, Hanna multi-parameter auto analyzer, Omega resistivity meter, electrodes, twelve volt battery, sieve, fine-grained sediment, sodium chloride and water.

A simulation tank (Figure 1) was constructed using acrylic and its interior lined with polythene to prevent possible leakage during the course of the experiment. The estimated volume of the tank is $522,000 \mathrm{~cm}^{3}$. It was filled with nearly homogenous sediment with grain sizes $\leq 1.18 \mathrm{~mm}$, corresponding to very coarse sand to colloid. The relatively uniform grain size distribution is expected to reduce inhomogeneities and possible spikes that could result from uneven distribution of materials during the passage of current through the model. The sediment was saturated with freshwater and the physico-chemical properties were measured using Hanna multi-parameter auto analyzer (Table 1). This procedure was repeated after introducing sodium chloride $(\mathrm{NaCl})$ into the model to attain a salinity of 15.67 practical salinity unit (psu) which represent brackish and estuary water. The initial volume of water is approximately $169,650 \mathrm{~cm}^{3}$ (169.65 liters), with $18 \mathrm{~cm}$ sediment thickness, approximately $234,900 \mathrm{~cm}^{3}$; and water column $6 \mathrm{~cm}$, approximately $78,300 \mathrm{~cm}^{3}$.

Table 1: Physico-chemical properties of water in the simulation tank

\begin{tabular}{|c|c|c|c|c|c|}
\hline Parameter & $\begin{array}{l}\text { Water } \\
\text { only }\end{array}$ & $\begin{array}{l}\text { Water } \\
\text { sand }\end{array}$ & $\begin{array}{l}\text { with Freshwater } \\
\text { (FWM) }\end{array}$ & $\begin{array}{l}\text { models Brackish } \\
\text { model (BWM) }\end{array}$ & $\begin{array}{c}\text { water } \% \text { change in FWM } \\
\text { and BWM }\end{array}$ \\
\hline Temperature $\left({ }^{\circ} \mathrm{C}\right)$ & 26.06 & 25.06 & 22.74 & 22.83 & 0.4 \\
\hline Salinity (psu) & 0.08 & 0.08 & 0.08 & 15.72 & 99.6 \\
\hline Pressure $(\mathrm{mmHg})$ & 723.9 & 724.2 & 728.2 & 728.1 & -0.01 \\
\hline Resistivity $\mathrm{m} \Omega \mathrm{cm}$ & 0.0056 & 0.0058 & 0.0066 & BDL & - \\
\hline Conductivity ( $\mu \mathrm{s} / \mathrm{cm})$ & 174 & 172 & 153 & 25420 & 99.4 \\
\hline TDS (mg/L) & 82 & 86 & 77 & 12730 & 99.4 \\
\hline DO (ppm) & 4.93 & 3.9 & 4.15 & 3.08 & -34.7 \\
\hline $\mathrm{pH}$ & 7.1 & 6.82 & 5.48 & 6.9 & 20.6 \\
\hline
\end{tabular}


(a)

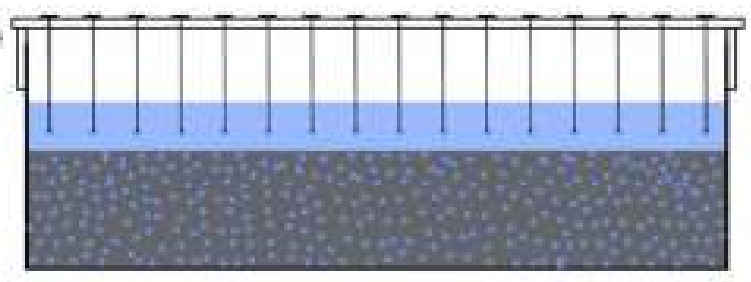

(b)

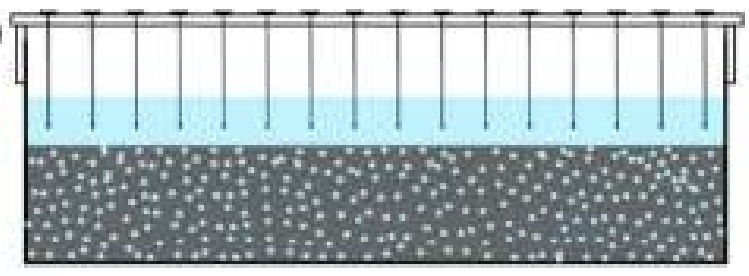

(c)

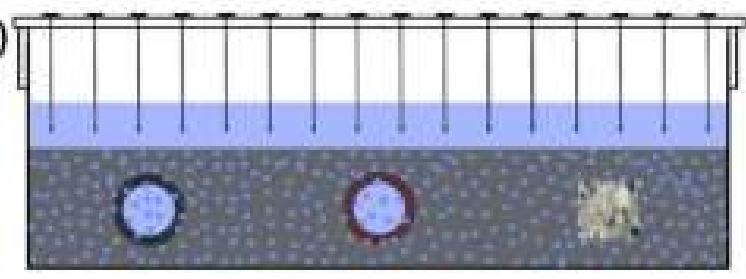

(d)

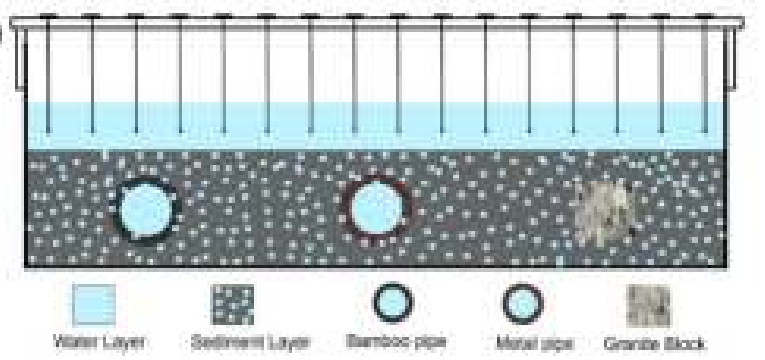

Figure 1: 2D illustrative diagram of Marine geoelectrical simulation tank setup in the laboratory. (a) Freshwater Static Model (b) Brackish Water Static Model (c) Freshwater Model with Buried Structure (d) Brackish Water Model with Buried Structure. Galvanized electrodes were lowered from the hanger into the water column.

Marine electrode towed streamer can be deployed either by dragging the cable on the seafloor or by using floating electrodes (Loke, 1996). The floating electrode configuration is adopted in this study to simplify the model. A wooden hanger perforated at $5 \mathrm{~cm}$ interval was used as holder to keep the electrode array in vertical position (Figure 1) over the water surface. The set-up was given time to stabilize and ensure uniform compaction within the system over a period of three days after which three channel-like structures filled with loose sediment were created in the compacted sediment. Resistivity measurements were made using the Omega resistivity meter.
Direct current (DC) was injected into the model through electrode pair designated as current electrodes ( $\mathrm{C} 1$ and $\mathrm{C} 2$ ), while the resulting potential drops were measured by potential electrode pair (P1 and P2). Horizontal profiling using dipole-dipole electrode configuration was used in this study. Dipole-dipole array utilizes four collinear electrodes; two currents and two potential electrodes. A profile length of $140 \mathrm{~cm}$, with interelectrode separation $5 \mathrm{~cm}$ was adopted. The spacing between the current electrode pair C1-C2 is given as ' $a$ ' which is the same as the separation between the potential electrode pair P1-P2 (Figure 2). The distance between current and potential electrode pairs is 'na', where $n$ is an integer $(1 \leq n \leq 5)$. In this array, the potential and the current may be interchanged according to the principle of reciprocity (Telford et al., 1990).

Geometric factor (K) and apparent resistivity $\rho_{\mathrm{a}(\mathrm{dd})}$ equations are:

$\mathrm{K}=\mathrm{na}(\mathrm{n}+1)(\mathrm{n}+2) \mathrm{n}--------------(1)$

$\rho_{\mathrm{a}(\mathrm{dd})}=\pi \operatorname{Ra}(\mathrm{n}+1)(\mathrm{n}+2) \mathrm{n}----------(2)$ 


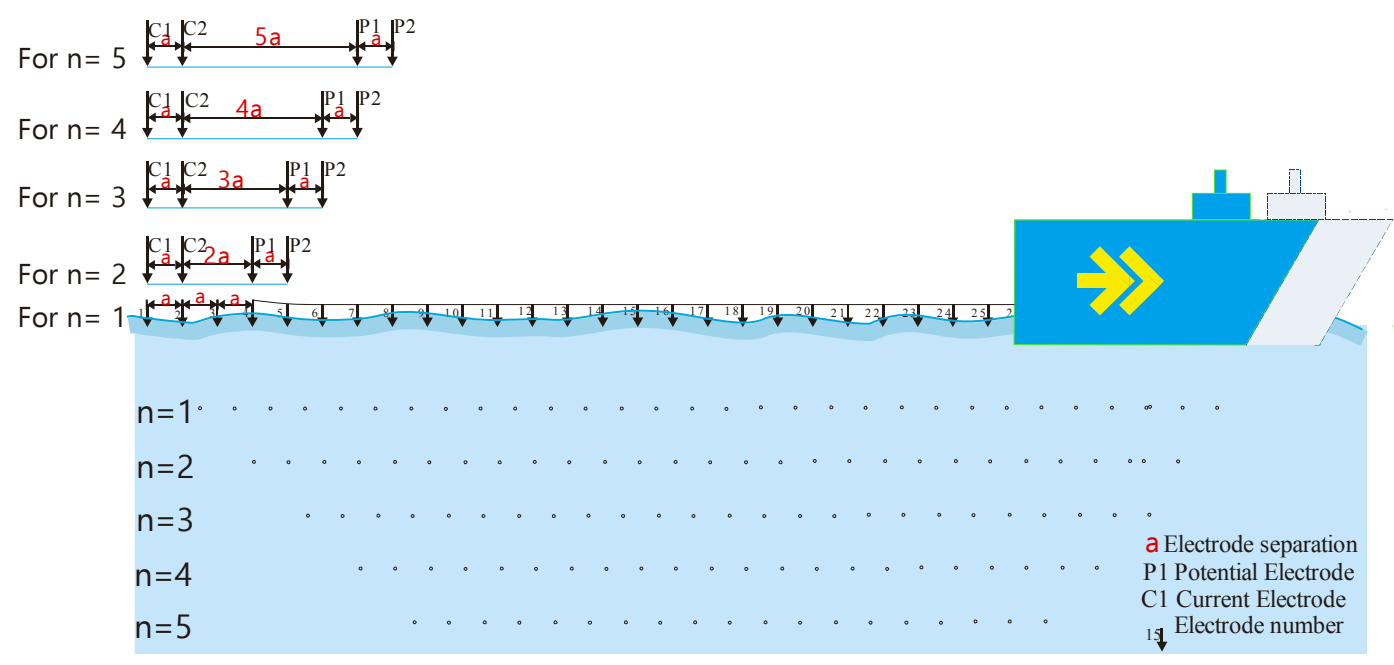

Where Geometric Factor $K=\pi n(n+1)(n+2)$ a

Figure 2: Schematic diagram of marine electrical resistivity data acquisition geometry using dipole-dipole electrode configuration and the progression of measurements used to generate a pseudo section.

Data processing was carried out using Dipro software. Apparent resistivity values were converted to true resistivity values by inversion using a non-linear leastsquare optimization technique (Loke and Barker, 1996; Loke and Dahlin, 2002). The obtained tomographic profiles were interpolated using kringing algorithm in order to produce a $2 \mathrm{D}$ contoured resistivity pseudosection. Results obtained from this study are presented as tables, chart and contoured resistivity pseudosection.

Description of models

Four models were designed for this study namely: Freshwater Static Model (FSM), Brackish Water Static Model (BSM), Freshwater Model with Buried Structures (FMBS), and Brackish Water Model with Buried Structures (BMBS) (Figure 1). For each of the models, salinity, conductivity, temperature and resistivity were measured (Table 1).

FSM (Figure 1a) is made up of fine-grained sediment saturated with fresh water, having salinity value of 0.08 psu. After uniform compaction within the simulation tank, sediment distribution was altered at stations $25-40,75-$ 95 and 120-140 respectively in order to create differential compaction which can be related to concealed river channels. No material was buried in the sediment and it therefore serve as a reference model to which other models can be compared.

FMBS (Figure 1c) is made up of fine-grained sediment saturated with fresh water having salinity value of 0.08 psu. Three objects (bamboo pipe, metal pipe and granite block) were buried in the sediment. The bamboo was buried between $15 \mathrm{~cm}$ and $30 \mathrm{~cm}$, the metal pipe between $60 \mathrm{~cm}$ and $90 \mathrm{~cm}$ and the granite between 100 $\mathrm{cm}$ and $120 \mathrm{~cm}$ along the transverse respectively.

BSM (Figure $1 \mathrm{~b}$ ) is characterized by similar structure as presented in the FSM but with higher salinity value of 15.72 psu as a result of the introduction of sodium chloride. No material was buried in the sediment and it therefore serve as the background model to which the FSM and FMBS models can be compared.

BMBS (Figure 1d) has similar structure as the FMBS except that the salinity is higher (15.72 psu) with the introduction of sodium chloride. The buried objects have same position as in the FMBS.

To ensure consistency and reliability of the result: (a) It was ensured that the electrodes have good contact with the water while taking the measurements; (b) throughout the experiment, electrode spacing was maintained; (c) value of the input current was maintained throughout the experiment; (d) electrodes were maintained in a vertical position to ensure a point source of current is delivered into the model through the water column; (e) spurious data obtained at some station positions were reacquired. Results and Discussions

Measurements obtained from the physico-chemical properties of the water are: temperature, salinity, surface pressure, resistivity, conductivity, TDS, DO and $\mathrm{pH}$ having values which ranges from $22.74{ }^{\circ} \mathrm{C}$ to $26.06{ }^{\circ} \mathrm{C}$, 0.07 to $15.72 \mathrm{psu}, 723.9$ to $728.2 \mathrm{mmHg}, 0.0056 \mathrm{~m} \Omega-\mathrm{cm}$ to $0.0066 \mathrm{~m} \Omega-\mathrm{cm}, 153 \mu \mathrm{s} / \mathrm{cm}$ to $25420 \mu \mathrm{s} / \mathrm{cm}, 77 \mathrm{mg} / \mathrm{L}$ to $12730 \mathrm{mg} / \mathrm{L}, 3.08 \mathrm{ppm}$ to $4.93 \mathrm{ppm}$ and 5.48 to 7.1 respectively (Table 1 ). Plot of the physico-chemical properties of water in the models were analyzed (Figure $3 a$ and $3 b$ ) in order to determine how the measured parameters influences change in resistivity. Salinity is directly related to conductivity, while conductivity is inversely proportional to resistivity. The introduction of sodium chloride into the model increase the salinity by $99.6 \%$ (Table 1), resulting to reduction in resistivity. This is considered the most important physico-chemical parameter which influences the resistivity, as the effect of surface pressure is negligible. There is $20.6 \%$ increase in $\mathrm{pH}$ and $34.7 \%$ reduction in dissolved oxygen (Table 1). However, negligible variation in resistivity and water depth observed could have been influenced by the temperature difference. It is understood that increase in temperature result to corresponding increase in conductivity, thereby decreasing the resistivity values. 
The salinity effect is observed to dominate other factors (Figure $3 b$ ).
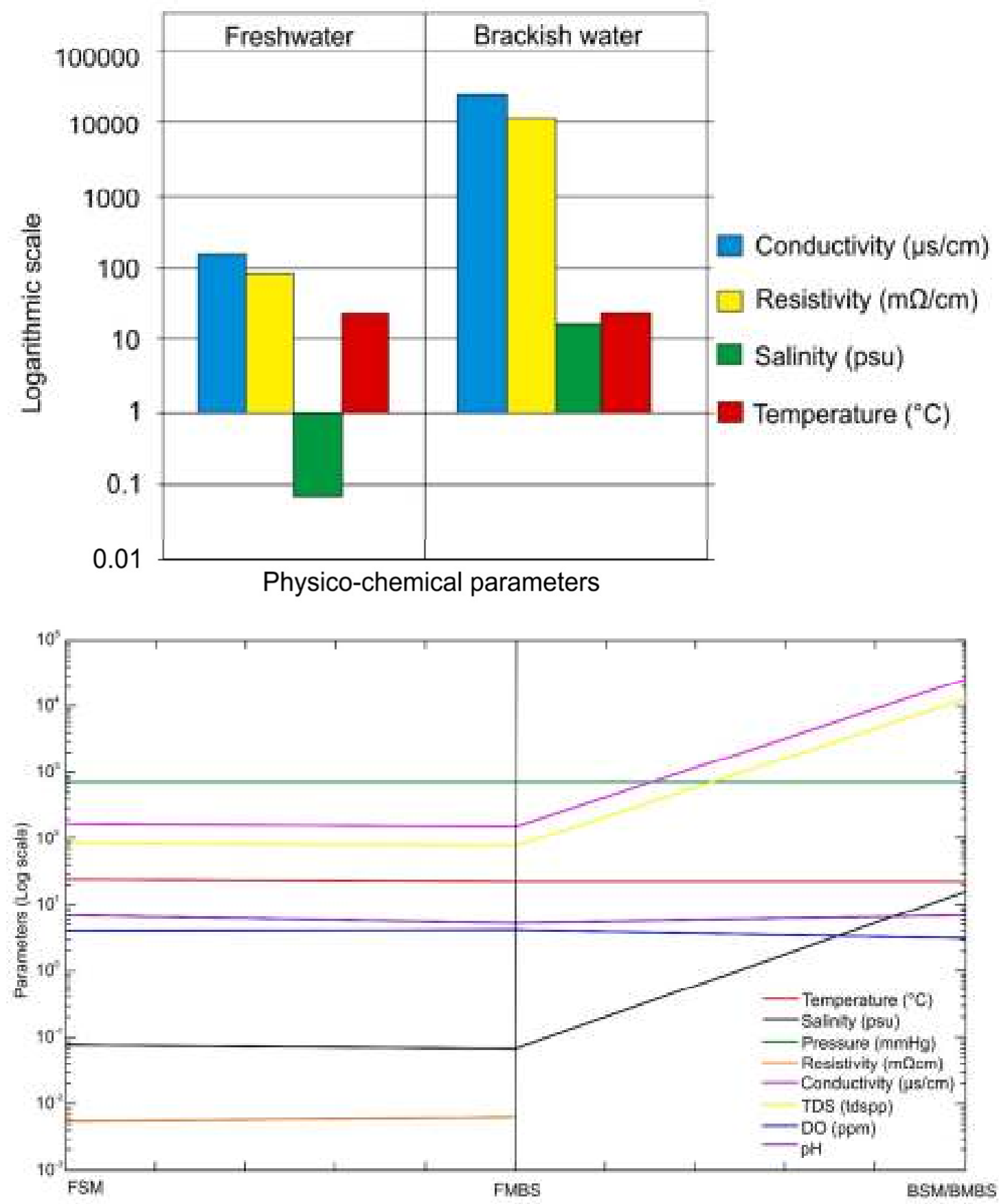

Figure 3: (a) Physico-chemical variation in fresh and brackish water models. (Note: logarithmic scale was used in the vertical axis). (b) Analysis of physicochemical parameters to evaluate effect of parameter on resistivity. Salinity, conductivity and TDS have dominant effect considering the magnitude of the range of values. Fine-grain sediment obtained from the seaside was sieved using 1.18 millimeter mesh. The sediment grain size in the model is therefore characterized by relatively uniform size distribution of very coarse sand to colloid. In order to determine the 2D resistivity structure along the profiles, inversion of the apparent resistivity data was carried out using Dipro. The resulting 2D resistivity structure was interpreted.

Result obtained for FSM represents the geoelectrical property of fresh water saturated sand (Figure 4). The resistivity structures generally delineate two layers, representing the water column and the sediment layer. The water column is characterized by relatively low resistivity values which are less than $59 \Omega \mathrm{m}$ and an average depth of approximately $4 \mathrm{~cm}$, as compared to the sediment layer with resistivity values which range between $26 \Omega \mathrm{m}$ and $110 \Omega \mathrm{m}$. In this FSM, high resistivity values in the sediment layer represent high compaction ( $\mathrm{HCZ})$, while low resistivity is equivalent to low compaction (LCZ). The vertical low compaction structures (LCZ) represent the concealed channel structures introduced into the model. It therefore reveals that marine electrical resistivity is efficient in sedimentology and analysis sedimentary structures. 
It can be applied to mapping concealed channels and geological structures below the water column.
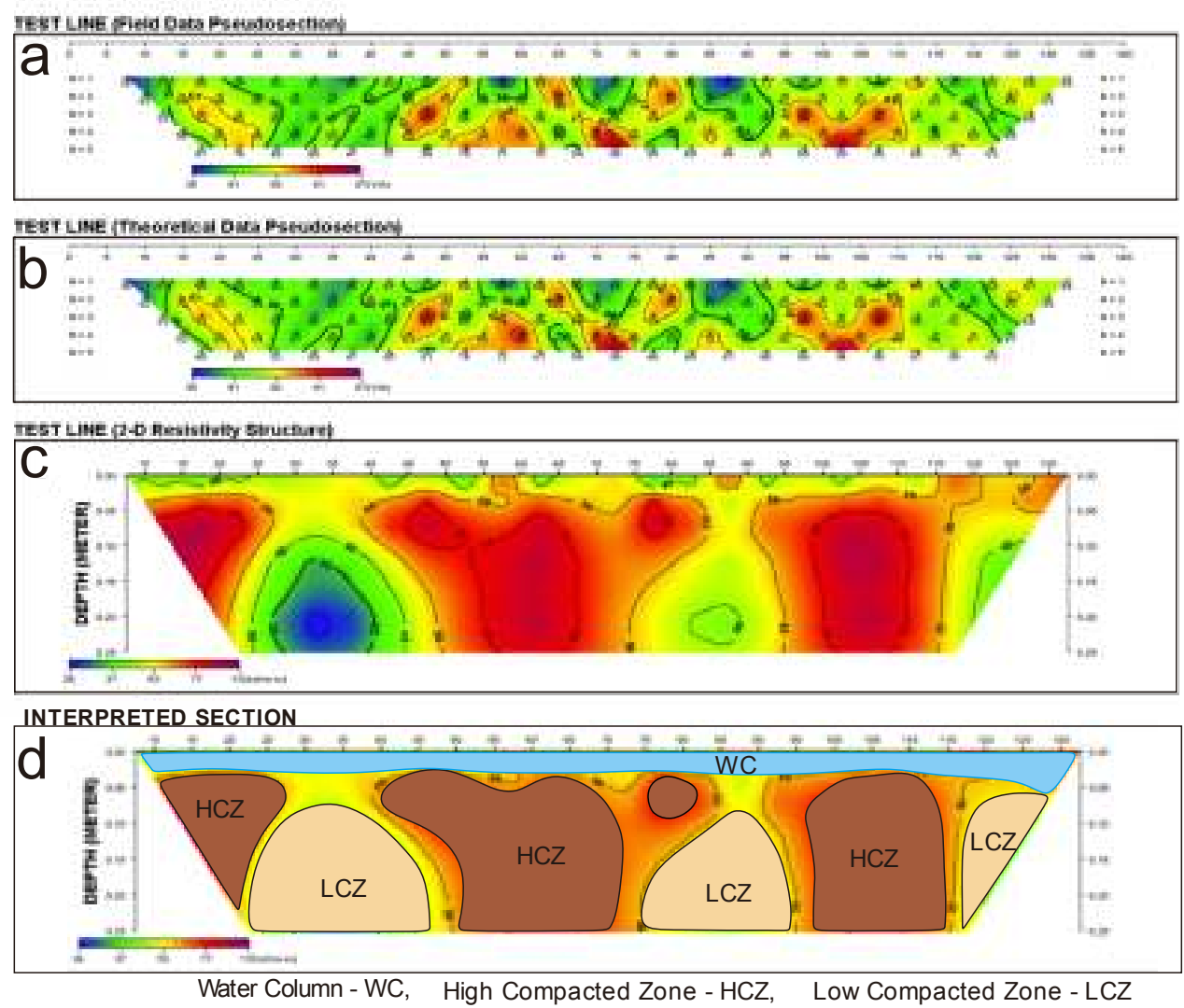

Figure 4: Representative model result obtained from freshwater static model using $5 \mathrm{~cm}$ inter electrode separation (a) Observed Data (b) Theoretical Data (c) 2D Resistivity Structure (d) interpreted section

Resistivity structures of BSM generally delineate two layers, representing the water column and the sediment layer (Figure 5). The water column resistivity value is less than $0.63 \Omega \mathrm{m}$, approximately $98.9 \%$ lower than that of the FSM (Table 1); but characterized by variable depth ranging from $5 \mathrm{~cm}$ to $9 \mathrm{~cm}$. The sediment layer is between $5 \mathrm{~cm}$ and $25 \mathrm{~cm}$ depth. The resistivity ranges between $0.63 \Omega \mathrm{m}$ and $12 \Omega \mathrm{m}$; approximately $89.1 \%$ to $97.6 \%$ reduction in resistivity as compared with that of FSM. The water column, sediment interface and the varying degrees of compaction in the sediment were efficiently delineated. 

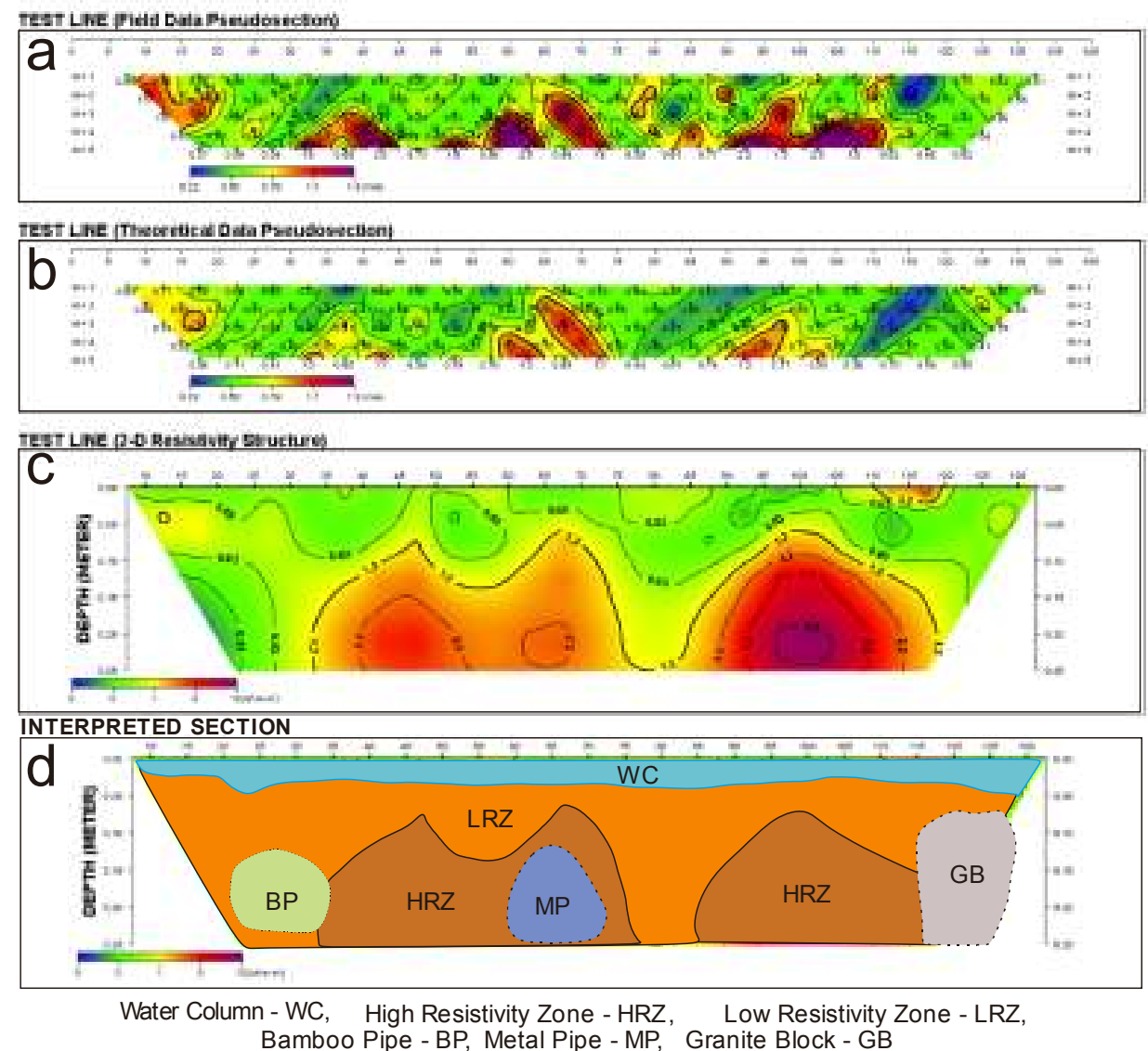

Figure 5: Representative model result obtained from Brackish Water Static Model using $5 \mathrm{~cm}$ inter electrode separation (a) Observed Data (b) Theoretical Data (c) 2D Resistivity Structure (d) interpreted section

Resistivity structures of FMBS generally delineate two layers (Figure 6), representing the water column and the sediment layer. The depth of the water column is approximately $4 \mathrm{~cm}$, characterized by resistivity values less than $66 \Omega \mathrm{m}$. This is approximately $10.6 \%$ higher than the value obtained for the FSM. It suggests a gradual resistivity transition between the water column and the sediment layer, influenced by the resistivity values of both layers. Resistivity values of the sediment layer with the buried structure ranges between $17 \Omega \mathrm{m}$ and $167 \Omega \mathrm{m}(4 \mathrm{~cm}$ and $25 \mathrm{~cm}$ along the profile). This increase in resistivity as compared with the FSM is basically influenced by the materials buried within the model. Thus, the resistivity of materials contained within a study area will generally determine the local minima and maxima. Two relatively low resistivity structures were identified in the sediment layer at $12 \mathrm{~cm}$ (stations $15-40$ ) and at $10 \mathrm{~cm}$ (stations $60-90$ ) respectively. The first structure represents the bamboo pipe characterized by resistivity values between $17 \Omega \mathrm{m}$ and $38 \Omega \mathrm{m}$. This result was influenced by saturating fluid which flows through the pipe. Thus, low contrast in resistivity hampered efficient delineation of the pipe walls. Similar incidence is recorded for the metal pipe in which resistivity values range from $17 \Omega \mathrm{m}$ to $38 \Omega \mathrm{m}$. Therefore, if the pipes are not closed at the two ends, resistivity of the fluid flowing through will greatly influence the resistivity values obtainable. We expect to obtain a different result when the pipes are closed at both ends. Relatively high resistivity value ranging from $86 \Omega \mathrm{m}$ to $167 \Omega \mathrm{m}$, at $4 \mathrm{~cm}$ to $25 \mathrm{~cm}$ (stations $100-120$ ) was obtained for the granite block. Since water could not flow through, internal part of the block is characterized by relatively lower resistivity values than the pipe walls. 

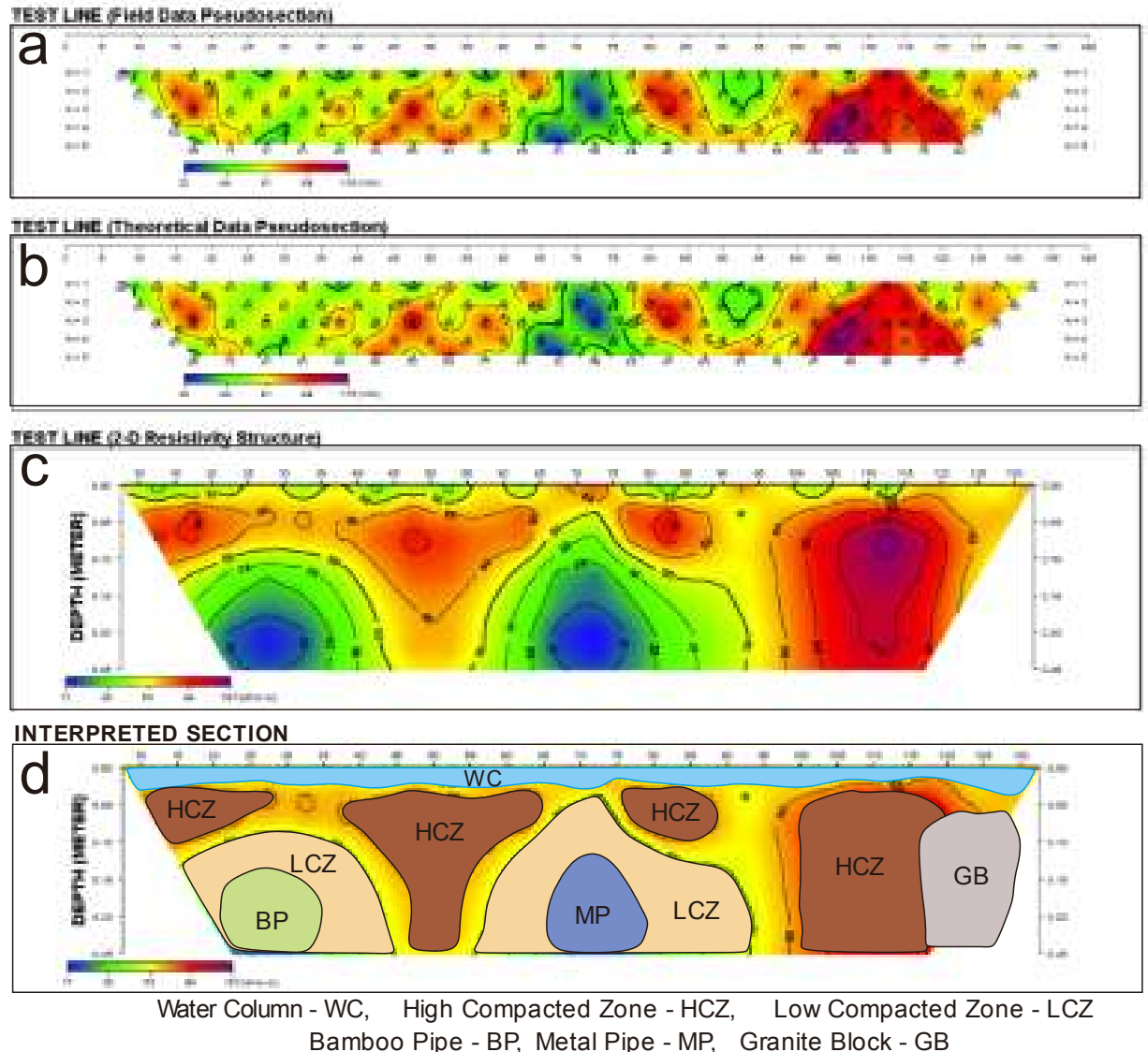

Figure 6: Representative model result obtained from freshwater model with buried structures (a) Observed Data (b) Theoretical Data (c) 2-D Resistivity Structure (d) interpreted section

In BMBS, variable water depth between $5 \mathrm{~cm}$ and $9 \mathrm{~cm}$ were obtained, and resistivity generally less than 0.63 $\Omega m$ (Figure 7). This is similar to the result obtained for the brackish water static model. Here, we considered that the resistivity of the buried structures becomes insignificant and does have a negligible effect on the water-sediment transition zone due to the higher salinity. Though variable depth was obtained, the depth estimate is observed to be deeper at stations 55 to 130 , while between stations 0 and 55 the water column could not be differentiated from the sediment layer. The sediment layer ranges from $5 \mathrm{~cm}$ to $25 \mathrm{~cm}$ depth. Resistivity values within the layers ranges between 0.63 and 12 $\Omega \mathrm{m}$. The bamboo pipe is not visible in the $2 \mathrm{D}$ resistivity structure (Figure 7). This is attributed to low contrast in resistivity between the medium and the material of the pipe. Since fluid could flow through the bamboo pipe, the possibility of absorbing the brackish water is there; thereby resulting in low resistivity contrast. We observe that mapping structures such as bamboo pipes which allow the saturating fluid to flow through will pose a great challenge in the marine environment, as compared with freshwater environment. However, when the two ends of the pipe are sealed and it has not absorbed much of the saturating fluid, it might be easier to map such structure. 

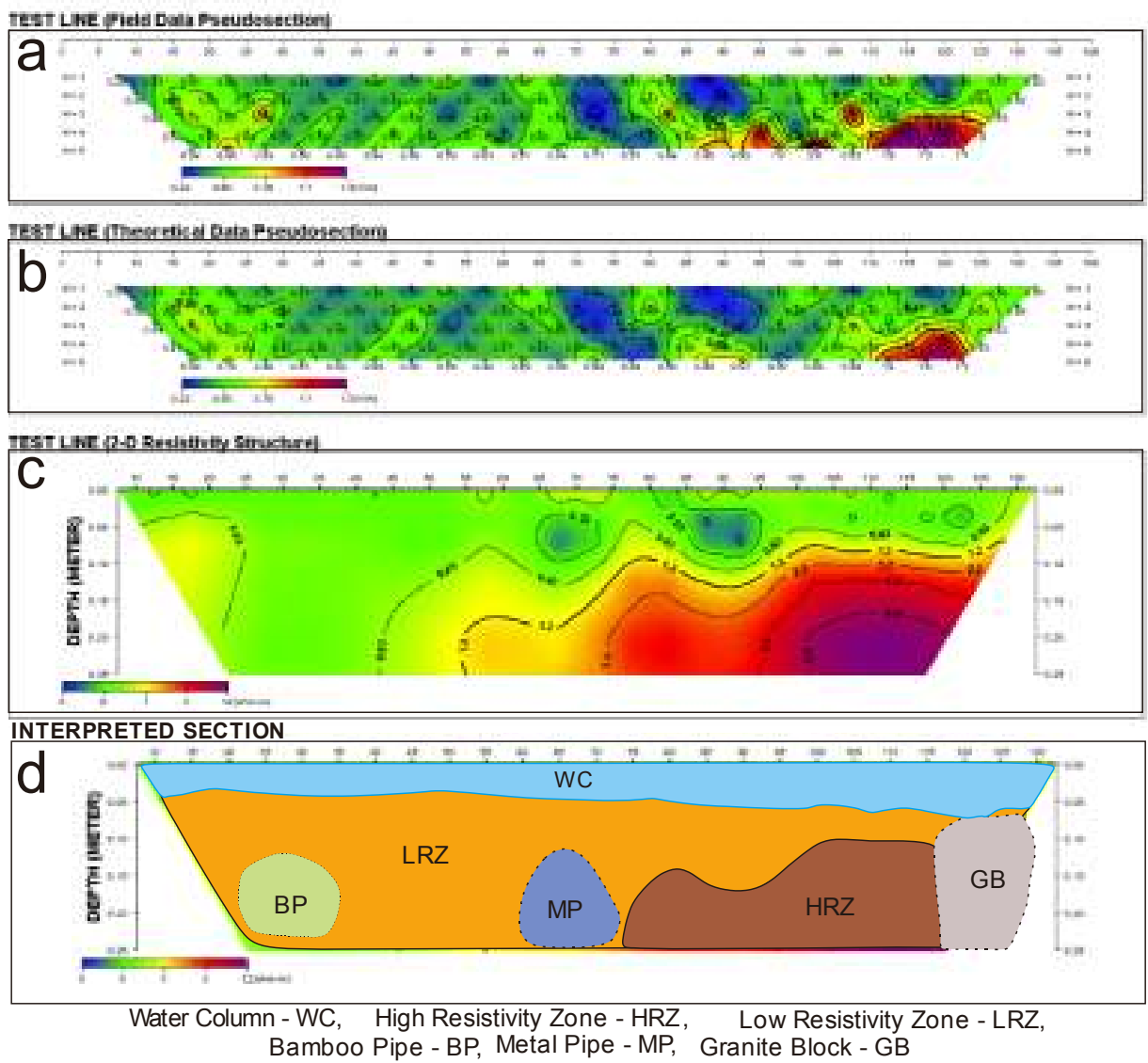

Figure 7: Representative model result obtained from brackish water model with buried structures (a) Observed Data (b) Theoretical Data (c) 2-D Resistivity Structure (d) interpreted section

The metal pipe positioned between station 60 and 90 is not properly resolved, due to the saturating fluid which flows through the pipe. The 2D resistivity structure (Figure 7 ) is characterized by relatively higher resistivity values above $1.2 \Omega \mathrm{m}$. The granite block situated between stations 100 and 120 is characterized by high resistivity values in the range $1.2 \Omega \mathrm{m}$ to $12 \Omega \mathrm{m}$. The block is much resolved, compared with the other two materials. This is attributed to the closed packed grain structure and high resistivity contrast with the saturating fluid. We can predict that basement structures and intrusive materials with closely packed grains will be easily resolved with marine electrical resistivity method. Analysis of geoelectrical responses of models Freshwater Static model and brackish water static model Result obtained for the static models aim to determine the efficiency of marine electrical resistivity (ER) method in delineating lithologic variation in fresh and brackish water environments. The low and high compacted areas were more efficiently resolved in the freshwater static model compared with the brackish water static model (Figure $8 \mathrm{a}$ and 8b). The low compacted sediment areas are likened to concealed river channels. Marine ER promises excellent result and can be employed in freshwater environment for environmental and engineering investigations. 

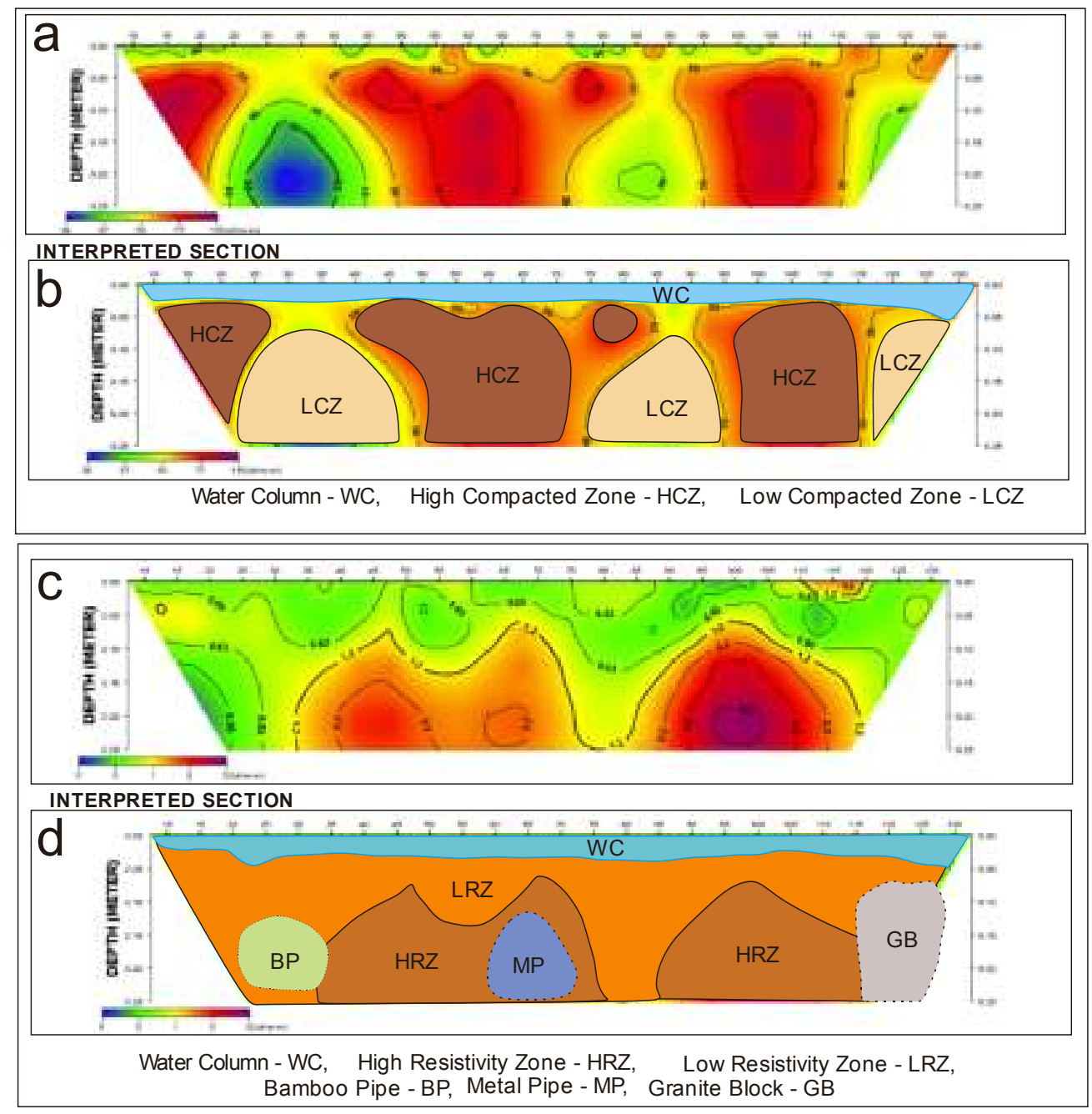

Figure 8: (a) 2-D resistivity structure of Freshwater Static Model (FSM) (b) Interpreted section of FSM (c) 2-D resistivity structure of Brackish Water Static Model (BMBS) (d) Interpreted section of BMBS.

Freshwater static model versus freshwater model with buried structures

Depth of the water column delineated in the two models is relatively the same. However, water resistivity in the static model is between $37 \Omega \mathrm{m}$ and $59 \Omega \mathrm{m}$, while it is between $30 \Omega \mathrm{m}$ and $66 \Omega \mathrm{m}$ in the BMBS (Figure 9a and b). The water column is better resolved in FSM as compared with FMBS based on the lateral continuity of the resistivity structure; though both show good correlation. The bamboo pipe (between stations 0 and 40 ) is characterized by resistivity values between $17 \Omega \mathrm{m}$ and $50 \Omega \mathrm{m}$, while the zone with low compaction in the static model has resistivity values between $26 \Omega \mathrm{m}$ and $46 \Omega \mathrm{m}$. We believe that marine ER will efficiently delineate buried structures in freshwater environment from the result obtained. In the case of the metal pipe (station $60-90$ ), resistivity values range between 17 $\Omega \mathrm{m}$ and $50 \Omega \mathrm{m}$. The inner closed contour line $22 \Omega \mathrm{m}$ represent saturating fluid flowing through the pipe. Thus we observe that marine ER will efficiently delineate buried metal pipes in freshwater environment. The static model has resistivity values greater than $77 \Omega \mathrm{m}$ which is attributed to high compacted sediment. The granite block is characterized by higher resistivity values which ranges between $66 \Omega \mathrm{m}$ and $167 \Omega \mathrm{m}$ compared to the high compacted sediment with resistivity greater than 77 $\Omega \mathrm{m}$. Therefore, marine ER promises to efficiently delineate bamboo pipe, metal pipe as well as granite block if deployed. However, the resolving ability will depend on the resistivity contrast between the saturating fluid and the buried object. 

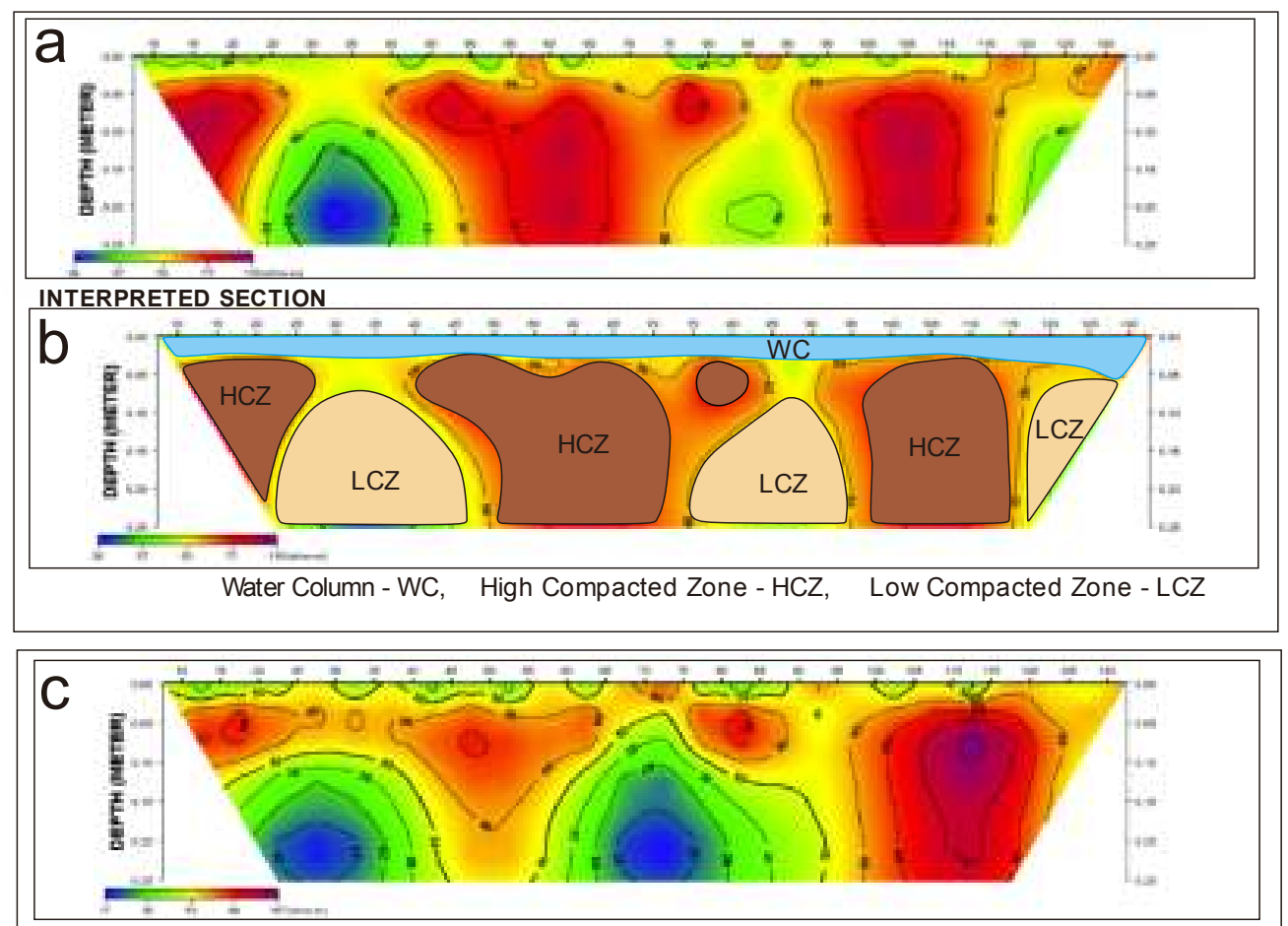

INTERPRETED SECTION

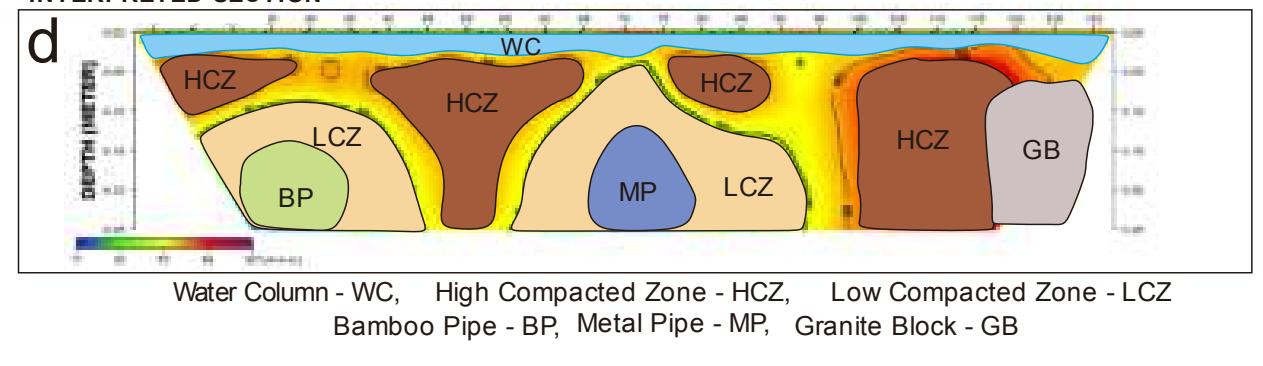

Figure 9: (a) 2-D resistivity structure of Freshwater Static Model (FSM) (b) Interpreted section of FSM (c) 2-D resistivity section of Freshwater Model with Buried structures (FMBS) (d) Interpreted section of FMBS.

Freshwater model with buried structures and brackish water model with buried structures

In this comparison, we aim to determine the environmental effect on mapping buried objects. The buried structures were efficiently resolved in the freshwater structured model (Figure 10a and 10b) compared with the brackish water structured model. Marine ER will be most efficient in freshwater environment. But when the resistivity contrast between the target structure and the saturating fluid is high, there is possibility of obtaining some reliable result. Generally, the efficiency of the marine ER is considered low in high salinity environment. We suggested further simulation to further establish and clarify this. 

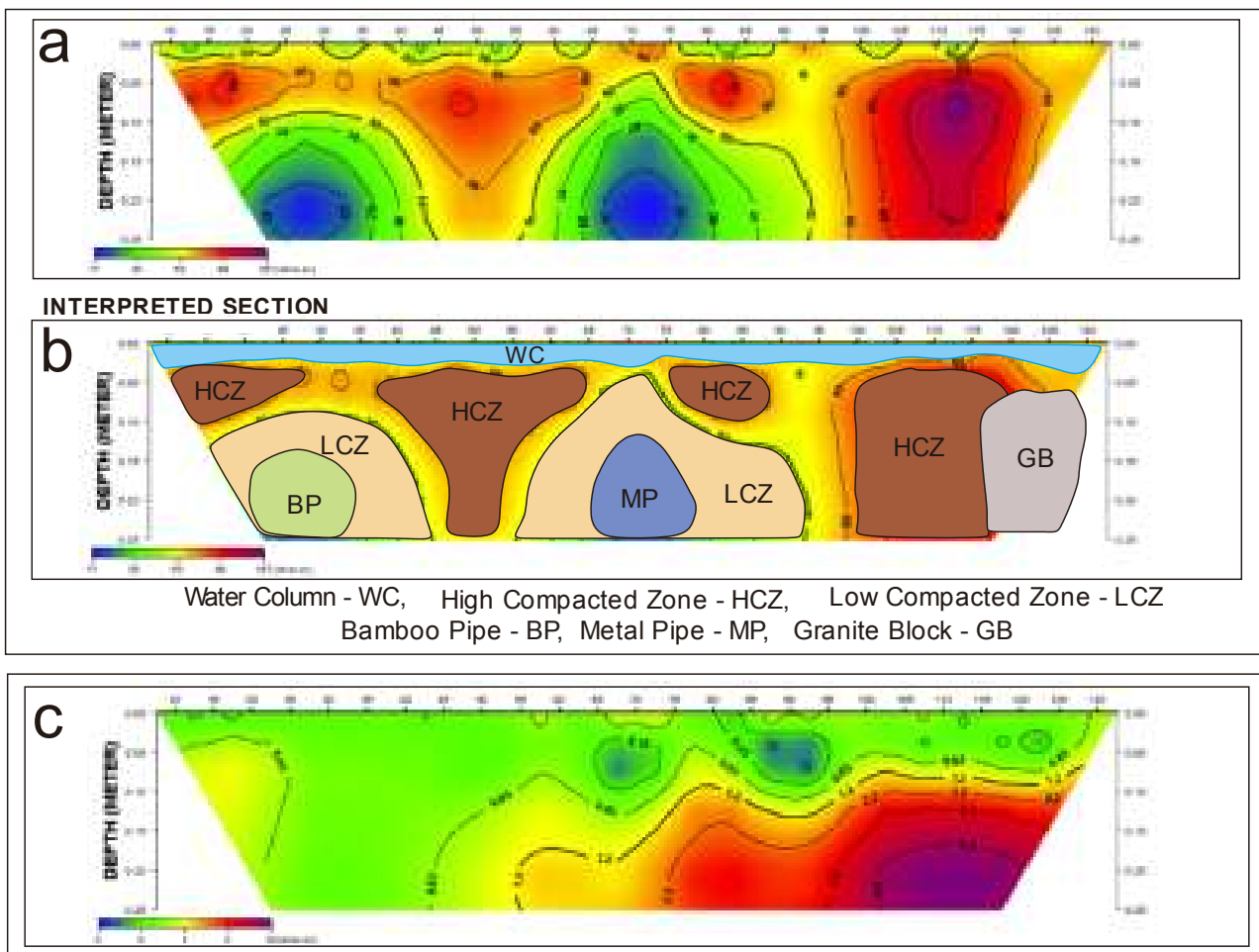

INTERPRETED SECTION

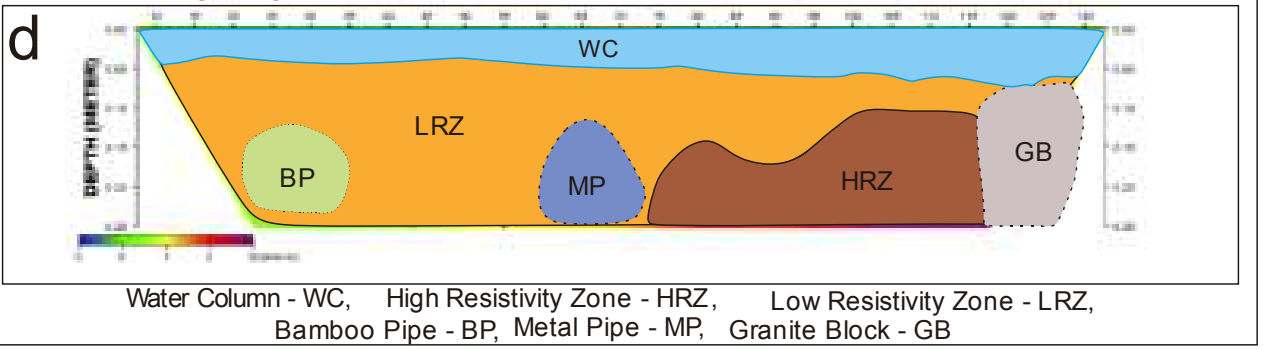

Figure 10: (a) 2-D resistivity structure of Freshwater Model with Buried structure (FMBS) (b) Interpreted section of FSM (c) 2-D resistivity section of Brackish water model with buried structure (BMBS) (d) Interpreted section of FMBS.

Brackish water static model and brackish water model with buried structures
Variable depth was obtained for the water column having resistivity which is generally less than $0.63 \Omega \mathrm{m}$ (Figure 11a and 11b). The efficiency of resolving the buried structures is low, as the bamboo pipe is not visible; while the metal pipe and granite block are only perceived from the structure contours. This further suggests low efficiency of the application in high salinity environment. 

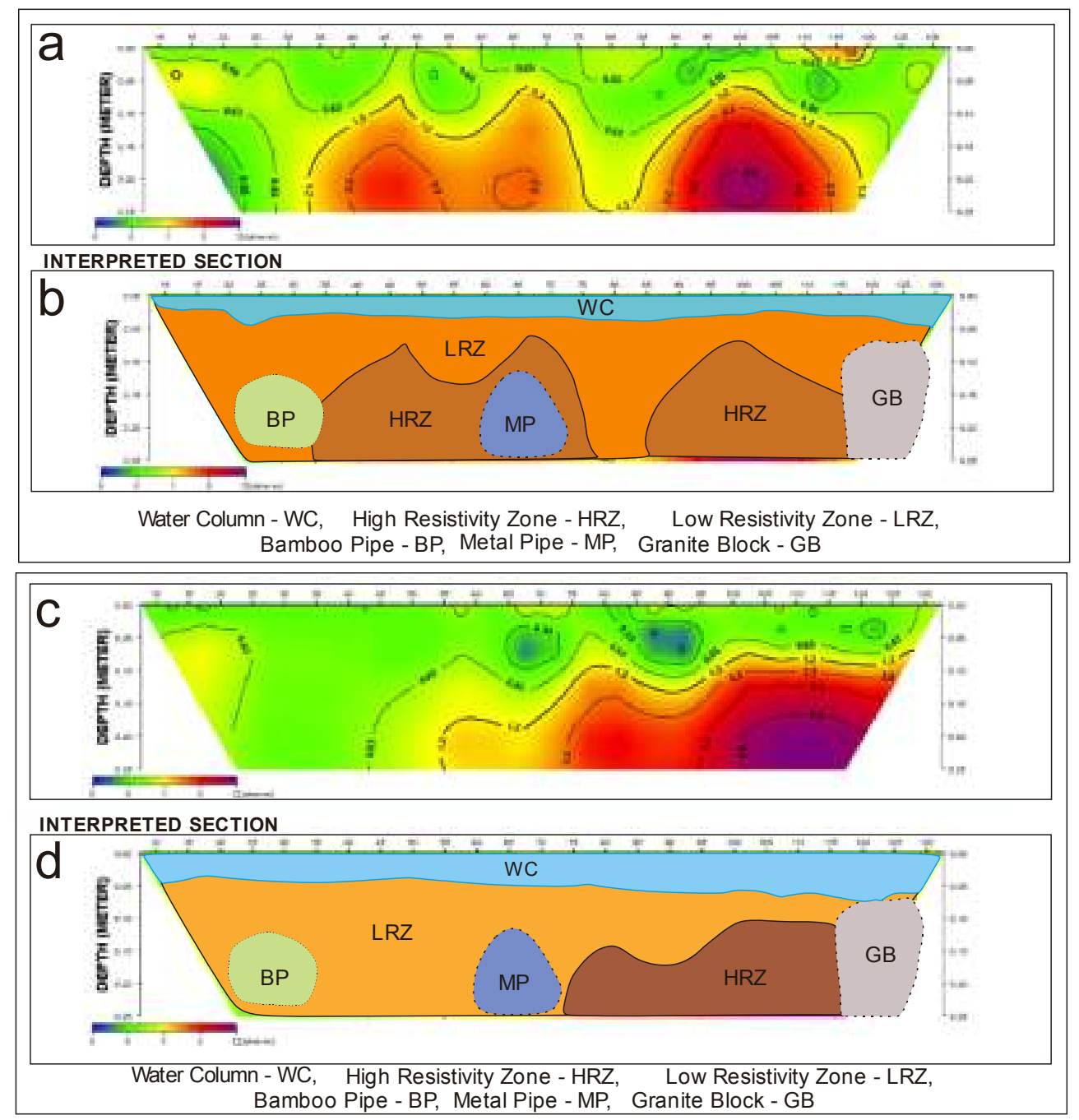

Figure 11: (a) 2-D resistivity structure of Brackish Water Static Model (BSM) (b) Interpreted section of FSM (c) 2-D resistivity structure of Brackish water model with buried structure (BMBS) (d) Interpreted section of FMBS.

\section{CONCLUSIONS}

Laboratory simulation of geoelectrical responses has been carried out over structures which include bamboo pipe, metal pipe and granite block. This experiment represent salinity variation in freshwater and brackish water environments. 2D geoelectrical sections obtained reveal that resistivity values in freshwater environment are relatively higher than in the brackish water environment. This is expected based on high salinity which characterizes the marine environment. We observed the possibility of obtaining resistivity measurement which are below detection limits of some measuring equipment; therefore need to redesign marine based resistivity recording equipment to detect very low resistivity values. From the FSM and BSM, varying degree of compaction, and water-sediment interface was efficiently mapped. Thus, this result can be applied to map geological structures characterized by non-uniform compaction, sedimentology studies, subsea engineering foundation investigation amongst others.

The bamboo and metal pipes were open-ended; therefore saturating fluid was able to flow through the pipes. This influenced the result obtained and limits the effective mapping of the structure boundary. Basement structures and intrusive rock materials with closely packaged grains were easily resolved using marine ER. This method will effectively delineate buried infrastructures depending on the resistivity contrast between the material and the saturating fluid. Reconnaissance studies to determine the properties of materials in an area of investigation should be carried before selecting a method to adopt, since resistivity anomaly is generally based on contrast. Analyses of preliminary results obtained by comparing environmental variables reveal that marine ER will be most efficient in freshwater and relatively low salinity environment. Marine electrical resistivity presents a suitable alternative to shallow seismic prospecting method in very shallow water.

\section{REFERENCES}

Adepelumi, A. A., Solanke, A. A., Sanusi, O. B., and Shallangwa, A.M., 2006. Model Tank Electrical Resistivity Characterization of Light Nonaqueous Phase Liquid migration in a clayeysand formation, Journal of environment Geology 50 (8): 1221-1223, DOI:10.1007/s00254-00602-z. 
Baumgartner, F., 1996. A new method for geoelectrical investigations underwater. Geophysical Prospecting 44: 7198.https://doi.org/10.1111/j.13652478.1996.tb00140.x

Baumgartner, F. and Christensen, N.B., 1998.Analysisand application of a nonconventional under water geoelectrical method in La ke Geneva, Switzerland. Geophysical Prospecting 46: 527541.https://doi.org/10.1046/i.13652478.1998.00107.x

Butler, S. L. and Sinha, G., 2012. Forward modeling of applied geophysics methods using Comsol and comparison with analytical and laboratory analog models. Computers and Geosciences, 42: 168-176. https://doi.org/10.1016/j.cageo.2011.08.022

Compare,V.,Cozzolino,M.,Mauriello, P., and Patella, D., 2009.Three-dimensional Resistivity Probability Tomography at the prehistoric site of Grotta Reali (Molise, Italy). Archaeological Prospection 16: 53-63.DOI: 10.1046/j.13652478.1998.00107.x

Henderson, R. D., Day- Lewis, F. D., Abarca, E., Harvey, C. F., Karam, H.N.,L iu, L. and Lane, J.W.J., 2010. Marine electrical resistivity imaging of submarine groundwater discharge: sensitivity analysis and application in Waquoit Bay, Massachusetts,USA.HydrogeologyJournal18: 173-185.https://doi.org/10.1007/s10040-0090498-z

Kaufmann, O., and Deceuster J., 2007. A 3-D resistivity Tomography study of a LNAPL plume near a gas station at Brugelette (Belgium). Journal of Environmental and Engineering Geophysics, 12: 207-219. https://doi.org/10.2113/JEEG12.2.207.

Kitson, P. 1996. The Evolution of Shallow Marine Data Acquisition in Canada. Recorder, Canadian Society of Exploration Geophysicists. Vol. 21, No 6.

Lelievre, P. G., and Oldenburg, D. W., 2006. Magnetic forward modelling and inversion for high susceptibility. Geophysical Journal International 166: $\quad 76-90$. https://doi.org/10.1111/j.1365246X.2006.02964.X

Leucci, G., Greco, F., DeGiorni, L., and Maceri, R., 2007. Three-dimensionalimageof seismic refraction tomography and electrical resistivity tomography survey in the castle of Occhiola (Sicily, Italy).JournalofArchaeologicalScience34: 233-

242.https://doi.org/10.1016/j.jas.2006.04.010.
Loke, M. H., 2001. Tutorial: 2-D and 3-D electrical imaging surveys, from pangea. stanford.edu:https://pangea.stanford.ed u/research/groups/sfmf/docs/D Resistivity_Not es.pdf accessed July 17, 2011.

Loke, M. H.,1996. Tutorial: 2-D and 3-D Electrical Imaging Surveys. Geotomo Software, Penang, Malaysia.

Loke, M. H. and Barker, R.D., 1996. Rapid leastsquares inversion of apparent resistivity pseudo sections by aquasi- Newton method. Geophysical Prospecting 44: 131- 152.

https://doi.org/10.1111/j.1365- 2478.1996.tb00142.x

Loke, M. H. and Dahlin, T.,

the Gauss- Newton and quasi-Newton methods in resistivity imaging inversion. Journal of Applied Geophysics 49: 149162.https://doi.org/10.1016/S09269851(01)00106-9

Miller, R. D., Markiewicz, R. D., Merry, C., Xia, J., Maples, C., 1995. Improvements in shallow high-resolution seismic reflection through PCbased systems. Computer Geoscience. 21: 957-964. Doi:10.1016/0098-3004(95)00032-4

Morakinyo A. M., 2015. Laboratory measurement and comparison of 2-dimensional resistivity imaging over two simulated geologic target. Department of Applied Geophysics, Federal University of Technology Akure, Nigeria. Unpublished Postgraduate Thesis.

Moradi, M., Hafizi, M. K., Taheri, B., Kamal, H.S., 2011, Application of geophysical methods to delineation of LNAPL contaminated plume. Proc. of the 7th IASME/WSEAS International Conference on Energy, Environment, Ecosystems and Sustainable Development and the 4th IASME/WSEAS International Conference on Landscape Architecture, Angers. Pp 135-139

Mosher, D. C., Simpkin, P. G., 1999. Status and trends of marine high-resolution seismic reflection profiling: data acquisition. Geoscience. Canada. 26:

174-187. https://journals.lib.unb.ca/index.php/GC/article/vi ew/4024.

Obikoya I. B. and Bennell J. D., 2012. Geophysical Investigation of the Fresh-Brackish Water Interface in the Coastal Area of Abergwyngregyn. Journal of Environmental Protection, 3: 1039-1046 http://dx.doi.org/10.4236/jep.2012.39121 
Olorunfemi, M. O., Olayinka, A.I., and Akinluyi, F.O., 2001. Laboratory Measurement and inversion of the 2-D Geoelectric response of a HydrocarbonImpacted Sand Formation. Global Journal of Pure and Applied Science. 7(4): 695-705

Passaro, S., 2010. Marine electrical resistivity tomography for shipwreck detection in very shallow water: a case study from Agropoli (Salerno, southern Italy). Journal of Archaeological Science 37: 1989-1998. https://doi.org/10.1016/j.jas.2010.03.004

Sheriff, R.E., 1977. Limitations on resolution of seismic reflections and geologic detail derivable from them. In: Payton, C. E. (Ed.),Seismic Stratigraphy Applications to Hydrocarbon Exploration. American Association of Petroleum Geologists Memoir26: 3-14.
Shtivelman, V., 2001. Shallow water seismic surveys for site investigation in the Haifa Port Extension area, Israel. Journal of Applied Geophysics. 46: 143-158.https://doi.org/10.1016/S09269851(01)00034-9

Subba R, C. and Chandrashekhar V., 2014. Detecting oil contamination by Ground Penetrating Radar around an oil storage facility in Dhanbad, Jharkhand, India. Journal Industrial Geophysical Union. 18 (4): 448-454

Telford, W.M., Geldart, L.P., and Sheriff, R.E.,1990. Applied Geophysics: Cambridge University press.

Yang, C. H., You, J. I., and Lin, C. P., 2002. Delineating Lake Bottom structure by resistivity image profiling on water surface. Terrestrial Atmospheric and Oceanic Sciences 13(1): 3952.DOI: 10.3319/TAO.2002.13.1.39(T) 